\title{
Leonardo Secchi. Análise de Políticas Públicas: Diagnóstico de Problemas, Recomendação de Soluções. São Paulo: Cengage Learning, 2016.
}

Augusto Junior Clemente ${ }^{1,2}$

Esta resenha tem dois objetivos: (i) apresentar o livro de Leonardo Secchi - Análise de Políticas Públicas: diagnóstico de problemas, recomendação de soluções (São Paulo: Cengage Learning, 2016, 238 páginas); e (ii) realizar uma reflexão crítica sobre a organização curricular e as práticas de ensino nos bacharelados em Ciências Sociais no Brasil, sobretudo, com ênfase em Ciência Política. O fio condutor da resenha está na reflexão do próprio labor docente em Ciências Sociais tendo como mote a seguinte provocação: a educação em nível superior é apenas ensino de conteúdos ou também de procedimentos, habilidades e competências? O livro de Secchi ajuda a refletir sobre esta questão.

Reconhecidamente um especialista em políticas públicas, o autor do livro possui Ph.D em Estudos Políticos pela Universidade de Milão (Itália) e Pós-Doutorado em Políticas Públicas pela Universidade de Wisconsin-Madison (EUA). Atualmente, é professor na Escola Superior de Administração e Gerência (Esag) na Universidade do Estado de Santa Catarina (Udesc), possuindo ampla produção acadêmica e uma trajetória de excelência sobre o assunto.

Formatado para ser um manual prático, o livro de Secchi serve de suporte "metodológico-prático" e não apenas de aparato "teórico-conceitual". O texto é escrito de forma objetiva e atrativa, compondo um roteiro do "como fazer" análise de política pública, tendo, como público-alvo: o "estudante ou servidor público, que precisa de métodos, técnicas e exemplos muito aplicados nas atividades de diagnóstico de problemas, projeções de resultados,

Professor Adjunto do Bacharelado em Administração Pública na Universidade Federal do Paraná (UFPR), Curitiba, Paraná, Brasil.

2 Professor Adjunto do Programa de Pós-Graduação em Políticas Públicas na Universidade Federal do Pampa (Unipampa), Bagé, Rio Grande do Sul, Brasil. E-mail: <augustoclemente@ymail.com> Revista Brasileira de Ciência Política, nº 26. Brasília, maio - agosto de 2018, pp 313-322. 
mediações de processos participativos e recomendação de política pública" (SECCHI, 2016, p. xiii).

O livro é a continuidade de outra obra do mesmo autor: Políticas públicas: conceitos, categorias de análise, casos práticos. Contudo, se neste último Secchi (2013) esboça os principais conceitos e teorias sobre a ciência da política pública, no livro aqui resenhado, ele nos presenteia com questões procedimentais e práticas que vão do diagnóstico de um problema público à confecção final de um relatório de recomendação de política pública destinado ao tomador de decisão.

Apenas na introdução do livro - o capítulo 1 - há um pouco teorias e conceitos, para localizar sucintamente o contexto da área de conhecimento ao leitor menos afeito ao tema. O capítulo 2 trata da análise do problema público (problem analysis) e, em seguida, no capítulo 3, o autor ensina como devemos proceder à escolha da abordagem mais adequada para a análise das soluções (solution analysis) do problema público diagnosticado. São duas as abordagens apresentadas: a racionalista (esboçada no capítulo 4) e a argumentativa (tratada no capítulo 5). Por fim, no capítulo 6, Secchi demonstra qual deve ser a estrutura de um relatório de análise de política pública, ou seja, o produto final que o analista deve entregar ao destinatário que demanda o seu trabalho. Aqui a preocupação é quanto ao tipo da linguagem e ao "desenho" do relatório - distinto em ambos os aspectos dos trabalhos acadêmicos. Ainda, o livro traz como anexo dois modelos de relatório de análise de políticas públicas: um aderente à abordagem racionalista e outro à abordagem argumentativa.

Para além de trazer vários exemplos criativos e didáticos sobre o conteúdo trabalhado, o livro também contempla exercícios de fixação ao fim de cada capítulo. Trata-se de um passo necessário para um texto que objetiva ser um manual prático, mas que exige muita competência docente de quem o faz.

Como o livro não é um texto tradicionalmente científico (nem do ponto de vista teórico, nem do ponto de vista empírico), ele não tem um capítulo conclusivo, o que é perfeitamente compreensível, tendo 
em vista os objetivos da obra, mesmo porque as considerações do autor sobre o objetivo do livro já estão lançadas na introdução.

Uma vez apresentada a estrutura da obra, cabe ressaltar alguns dos seus pontos fundamentais, começando pela forma como é definida a análise de políticas públicas: "a atividade e o campo de conhecimento teórico e metodológico voltados para a geração e a sistematização de conhecimentos aplicados ao enfrentamento de problemas públicos" (SECCHI, 2016, p. 1). Ela envolve análise de problemas (problem analysis) e análise de soluções (solution analysis) "para auxiliar na estruturação de políticas, leis, programas, campanhas, projetos ou ações públicas" (op. cit.). Portanto, a análise de políticas públicas auxilia no aperfeiçoamento da formulação, decisão e posterior implementação de uma ação pública.

O problema público está para a doença, assim como a política pública está para o tratamento. Metaforicamente, a doença (problema público) precisa ser diagnosticada, para então ser dada uma prescrição médica de tratamento (política pública), que pode ser um remédio, uma dieta, exercícios físicos, cirurgias, tratamento psicológico, entre outros (instrumentos de política pública) (SECCHI, 2016, p. 5).

O trabalho de um analista de políticas públicas é o de delimitar o problema público, gerar alternativas consistentes, projetar custos e benefícios, e dissolver (ou antecipar) conflitos de interesses: "tudo isso para evitar a repetição, imitação, preconceito ou autointeresse. Sair do achismo para evitar falhas de implementação (implementation gaps)" (SECCHI, 2016, p. 3).

Como ressaltado anteriormente, as opções de abordagens de análise de políticas públicas que Secchi oferece são duas: a racionalista e a argumentativa. A primeira é de base epistemológica positivista, que tem como princípio norteador a adequação entre fins e meios, a projeção de resultados e foco na satisfação do maior grau de bem-estar em termos de sua utilidade. Sua ascensão se deu na década de 1970 nos EUA: 
Durante o governo Ronald Reagan, a entrega de relatório de análise de política pública foi alçada a requisito para aprovação de qualquer projeto de lei que implicasse custos para o governo federal. O objetivo era evitar a aprovação de projetos públicos que não passassem por uma análise de custo-benefício (SECCHI, 2016, p. 13)

Na década de 1980, contudo, a abordagem argumentativa começa a se desenvolver a partir das áreas da Filosofia e das Ciências Sociais. Mas só nos anos 1990 é que o pluralismo teórico-metodológico ocorreu a partir da "virada argumentativa" e seus modelos calcados na epistemologia do construtivismo social. Enquanto o analista racionalista tenta moldar o mundo político à lógica científica e técnica, o argumentativista se preocupa mais em:

reforçar o debate teórico e epistemológico do que construir uma "receita de bolo" metodológica [...] os racionalistas esperam do analista o papel de investigação, análise, síntese e apontamento de recomendações de política pública, enquanto que o analista pós-positivista [argumentativista] é chamado para mediar interesses, facilitar a participação dos atores, auxiliando-os a formular e expressar seus argumentos (SECCHI, 2016, p. 16).

A maneira pela qual se deu a constituição da ciência da política pública (policy sciences) é outro ponto retomado por Secchi. O autor informa muito bem ao leitor em que lugar se situa o papel do analista, relembrando as quatro dimensões da policy sciences: (i) pesquisa de política pública (policy research): que foca no avanço do conhecimento sobre como as políticas públicas se desenvolvem na prática; (ii) teoria da escolha pública (public choice theory): que busca a construção teórica dedutiva, sendo derivada da teoria econômica sobre a produção de bens públicos; (iii) avaliação de políticas públicas (policy evaluation): que é de caráter retrospectivo para a manutenção, ajustes ou extinção de políticas públicas; (iv) a 
análise de políticas públicas (policy analysis): a atividade de suporte à tomada de decisão em política pública, de caráter prescritivo e métodos prospectivos para a elaboração, projeção de resultados e recomendação de políticas públicas. No ciclo de políticas públicas, a policy analysis - objeto do livro - foca o processo compreendido entre a identificação de um problema público, a formação da agenda e a formulação de alternativas.

As universidades desempenham, em regra, a policy research $\mathrm{e}$ dão maior ênfase à dimensão acadêmica. Enquanto que a policy evaluation e a policy analysis ficam muito mais a cargo dos institutos de pesquisa (públicos e privados), governos e think tanks. Contudo, pouca atenção tem sido dada à formação desses profissionais no Brasil, sobretudo, nas Ciências Sociais.

o perfil de pesquisa universitária em ciências sociais no Brasil é mais próximo da policy research. No entanto, já são visíveis os avanços da policy analysis em cursos de mestrado profissional e grupos de pesquisa nas áreas de planejamento urbano, saúde, educação e administração pública, que estão mudando o foco e o método de pesquisa voltada para a aplicação/recomendação prática, além de revisões do modelo de seus relatórios e dissertações para que sejam parecidos com um relatório de política pública (SECCHI, 2016, p. 21).

A função de análise de políticas públicas no Brasil está em consonância com o contemporâneo processo de amadurecimento do Campo de Públicas: nova área interdisciplinar que teve suas Diretrizes Curriculares Nacionais (DCNs) recém-criadas em 2014 (BRASIL, 2014). O Campo de Ciências Públicas congrega cursos voltados para a formação de profissionais que irão compor os quadros do setor público estatal e não estatal: Administração Pública, Gestão Pública, Gestão Social e Políticas Públicas. Segundo Secchi, tais cursos, no Brasil, já somam mais de 200 entre graduação e pós-graduação. Acrescenta-se a essa empreitada escolas de governo: Escola de Administração Fazendária (Esaf) e Escola Nacional de 
Administração Pública (Enap), bem como o surgimento de entidades profissionais (não apenas acadêmicas): Associação Nacional dos Especialistas em Políticas Públicas e Gestão Governamental (Anesp) (SECCHI, 2016).

Trata-se de um movimento que vai ao encontro da criação de carreiras na gestão pública, como a de Especialista em Políticas Públicas e Gestão Governamental no nível federal. Organizações como o Instituto de Pesquisa Econômica Aplicada (Ipea) e o Centro Brasileiro de Análise e Planejamento (Cebrap) também contratam o analista de Políticas Públicas. No plano internacional, tal função pode ser encontrada em órgãos multilaterais: Organização Internacional do Trabalho (OIT), Organização Mundial da Saúde (OMS), etc. $\mathrm{O}$ trabalho de análise de políticas públicas também pode ser desempenhado por assessores parlamentares ou ativistas de ONGs e Movimentos Sociais (op. cit.).

Duas críticas podem ser feitas ao livro de Secchi, ambas relacionadas às abordagens escolhidas pelo autor como as mais pertinentes para o analista de políticas públicas: a primeira é que a abordagem racionalista é mais detalhada e aprofundada no livro em relação à argumentativa - o que fica evidente pelo número de paginas dedicado a cada uma nos seus respectivos capítulos: 58 para a racionalista e 31 para a argumentativa. Tal fato pode ser explicado pela natureza epistemológica da primeira, que a torna mais próxima das ferramentas de gestão. Contudo, a abordagem argumentativa extremamente complexa e rica - teve um tratamento reducionista na obra, frustrando as expectativas do leitor.

A segunda crítica é que parece haver certa confusão teórica no livro, dando a entender, em alguns momentos, que os processos participativos ou deliberativos podem ser similares aos modelos competitivos de democracia. Ao explicar sobre os estilos de decisão na abordagem argumentativa, o autor nos fala: "Basicamente existem dois estilos: o modelo de decisão (agregação de preferências) e o modelo deliberativo (construção de consensos)" (SECCHI, 2016, p. 137). O primeiro estilo, em realidade, é o modelo do velho pluralismo dos anos 1950 e 1960 que partia da noção de um indivíduo 
autointeressado que replicaria nos espaços participativos o mesmo comportamento competitivo oriundo das arenas eleitorais, em que os resultados das contendas seriam dados pelas "agregações das preferências". Dificilmente esse estilo de decisão - mais afeito à abordagem racionalista - pode ser combinado com a proposta do construtivismo social dos anos 1980 e 1990, nos quais se assentam os modelos de democracia participativa e deliberativa.

Os modelos de democracia participativa e deliberativa (de inspiração habermasiana) criticam o modelo calcado na competição e no conflito. Importam para aqueles as trocas de "razões" tendo em vista a concertação. No Brasil, temos boas experiências dessas práticas de gestão pública com os Orçamentos Participativos (OP). No OP de Belo Horizonte existe, por exemplo, a Caravana de Prioridades, na qual os delegados visitam outras comunidades e regiões da cidade com vistas a desenvolverem alteridade, o que tem como efeito a revisão das proposições de suas próprias regiões em substituição às demandas mais emergenciais de outras comunidades (PREFEITURA DE BELO HORIZONTE, 2014).

Essas fragilidades do livro nada tiram seus méritos. A sua maior contribuição, para o autor destas linhas, está em demonstrar como os bacharelados em Ciências Sociais - especialmente na ênfase em Ciência Política - podem ter sua natureza reorientada para um perfil mais profissional: "No Brasil temos um exército de cientistas sociais realizando pesquisa teórica com pouca aplicação prática [...] paralelamente, temos um setor público carente de conhecimento" (SECCHI, 2016, p. xi). Usando o termo do autor, o livro ajuda na construção de uma "ponte" entre estes dois mundos (o da academia e o do setor público), uma ponte que está na "vocação" original do surgimento da área de políticas públicas.

Em regra, os bacharelados em Ciências Sociais no Brasil não têm uma preocupação voltada para a formação de um egresso apto para ofício não acadêmico, o que se reflete em parco preparo dado aos estudantes que têm um perfil mais voltado para outro labor que não o de docente do magistério superior, com pouca ou nenhuma carga horária destinada a disciplinas aplicadas. 
As Ciências Sociais sempre sofreram com o problema da evasão e da retenção de seus discentes (VILLAS BOAS, 2003), algo que poderia ser mitigado se os cursos tivessem uma preocupação maior com o perfil do egresso, tendo em vista o preparo para o mundo do trabalho, que é a realidade mais sincera que os discentes irão encontrar quando se formarem. Obviamente que a resolução do problema da evasão nas Ciências Sociais a partir de um perfil profissional é uma hipótese, mas que surge da comparação com outras áreas que oferecem uma possibilidade de carreira para além da puramente acadêmica ${ }^{3}$. O desafio é o de reduzir o gap existente entre as expectativas dos discentes ao iniciarem o curso com a realidade factual do mundo pós-universidade.

Nos grandes centros urbanos e departamentos consolidados, esses problemas podem ser menores ou, mesmo, relativizados. Mas com a expansão dos parques universitários da última década novos cursos de Ciências Sociais surgiram no interior do País e em universidades privadas. Nesses casos, há uma pressão muito maior na justificativa de existência dos cursos - mormente no atual momento de estrangulamento econômico. Em tais realidades os projetos político-pedagógicos dos bacharelados devem demonstrar de que maneira serão absorvidos e, posteriormente, inseridos os estudantes na sua própria região, contribuindo para o desenvolvimento local, bem como compensar os investimentos alocados (inclusive do estudante de instituição privada).

A exemplo do que vem ocorrendo no campo de Públicas, devemos não apenas aguçar o senso crítico dos futuros cientistas sociais e políticos, mas oferecer a eles ferramentas de trabalho para exercerem o ofício que escolheram. Não podemos deixar os discentes "a sós", com suas próprias criatividades para poderem se inserir no "mercado" não acadêmico. Há perfis de alunos com diferentes aptidões: fato que precisa ser reconhecido. Pensar seriamente essas questões envolve mudanças nos atributos valorizados pela área, mudança dos perfis de professores a serem admitidos em

3 A comparação aqui feita é com base em cursos similares, como, por exemplo, o Serviço Social. 
concursos públicos e testes seletivos, bem como a "reciclagem" dos professores que já estão inseridos.

Como se esses fatos ainda não bastassem há, ainda, disputas epistemológicas sobre a natureza das Ciências Sociais, tal como o axioma da compreensão, defendido por Norberto Bobbio (2000): "o pesquisador consciencioso não quer, enquanto pesquisador, transformar o mundo; mas não quer, tampouco, enquanto pesquisador, conservá-lo. O seu único problema é compreendê-lo" (p. 78). Trata-se de um princípio normativo que coloca como única profissão possível a do pesquisador-professor. Uma visão de mundo que deve ser rediscutida. Não se quer, com essa crítica, fazer uma defesa de uma Ciência Social puramente tecnicista, muito menos discordar do caráter não intervencionista da produção do nosso conhecimento. A pesquisa em Ciências Sociais deve ser livre de juízos de valor, mas a formação do Cientista Social tem que ter o pé na realidade para poder intervir nela.

O quanto os bacharelados em Ciências Sociais avançariam se tivessem uma preocupação profissionalizante? Ensinamos Teoria dos Partidos, mas não sobre o trabalho de um militante profissional. Ensinamos Estudos Legislativos, mas não práticas de assessoramento parlamentar. Ensinamos Teorias da Democracia, mas não como organizar ou implementar um processo participativo e deliberativo. Ensinamos Teorias dos Movimentos Sociais, mas não como assessorar profissionalmente ONGs e demais organizações ativistas. Ensinamos sobre as relações entre Estado e Sociedade, mas não como atuar junto a grandes corporações como um lobista profissional. Mesmo quando ensinamos Políticas Públicas, ficamos somente no mundo das ideias. A lista aqui poderia ser enorme, mas, ao menos sobre a análise de políticas públicas, a obra de Secchi (2016) contribui para tapar um pouco dessa lacuna que deixamos na formação de nossos discentes. 


\section{Bibliografia}

BOBBIO, Norberto. Teoria geral da política: a filosofia e as lições dos clássicos. Michelangelo Bovero (Org.). Rio de Janeiro: Campus, 2000.

CUNNINGHAM, Frank. Teorias da democracia: uma introdução crítica. Porto Alegre: Artmed, 2009.

BRASIL. Ministério da Educação. Conselho Nacional de Educação. Câmara de Educação Superior. Institui as Diretrizes Curriculares Nacionais do curso de graduação em Administração Pública, bacharelado, e dá outras providências. Resolução n. 1, de 13 de Janeiro de 2014. Disponível em: <http://portal.mec.gov.br/index. php?option $=$ com_docman \&view $=$ download $\&$ alias $=14957$ rces001-14\&category_slug=janeiro-2014-pdf\&Itemid=30192>. Acesso em 5 jul. 2017.

PREFEITURA DE BELO HORIZONTE. Orçamento Participativo 2015/2016: metodologia e diretrizes. 2014. Disponível em: <http:// gestaocompartilhada.pbh.gov.br/sites/gestaocompartilhada. pbh.gov.br/files/biblioteca/arquivos/pb-0032-14e op_2015_2016_folder_5x8cm_20-08_los_1.pdf $>$. Acesso em 5 jul. 2017.

SECCHI, Leonardo. Análise de políticas públicas: diagnóstico de problemas, recomendação de soluções. São Paulo: Cengage Learning, 2016.

. Políticas públicas: conceitos, categorias de análise, casos práticos. 2. ed. São Paulo: Cengage Learning, 2013.

VILLAS BOAS, Glaucia K. Currículo, iniciação científica e evasão de estudantes de ciências sociais. Tempo social. São Paulo, v. 15, n. 1, p. 45-62, Apr, 2003. 